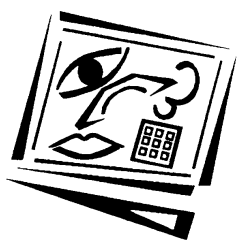

\title{
Instructional designers' conceptualisations of learning objects
}

\author{
David E. Francis \\ Saskatchewan Institute of Applied Science and Technology \\ Elizabeth Murphy \\ Memorial University of Newfoundland
}

\begin{abstract}
The purpose of the study reported on in this paper was to gain insight into how instructional designers conceptualise learning objects (LOs) and their attributes. It aimed to identify the range and types of conceptualisations of LO attributes held by a group of designers. Data were collected during two phases of semi-structured phone interviews with 10 instructional designers working in Canadian colleges and universities. Open, axial and selective coding were used to analyse data. Designers identified the following attributes of LOs: digital, interactive, pedagogically purposeful, pedagogically worthwhile, pedagogically assessable, usable, reusable, peer reviewable and granular. Designers conceptualised LOs and their attributes with more of a focus on pedagogical best practices rather than a focus on technical definitions of LOs.
\end{abstract}

\section{Introduction}

The phenomenon of instructional designers creating learning objects (LOs) is increasingly popular (Barritt \& Alderman, 2004; Downes, 2000-2008; McGreal, 2004; Wiley, 2002a). This popularity is evidenced by the number of LO repositories that have become available such as CAREO (CAREO Website, 2005-2007), CLOE (CLOE Website, 2005-2007) and MERLOT (MERLOT Website, 2005-2008). This popularity has grown despite a lack of consensus on what exactly constitutes a LO (Downes, 2003-2008; Friesen, 2004; McGreal, 2004; Wiley, 2002a).

Many definitions for LO have been proposed. For example, Wiley (2002a) defined a LO as "any digital resource that can be reused to support learning" (p. 6). Sosteric and Hesemeier (2004) defined a LO as "a digital file (image, movie, etc.) intended to be used for pedagogical purposes, which includes, either internally or via association, suggestions on the appropriate context within which to use the object" (p. 40). Alberta Learning defined a LO as follows:

\begin{abstract}
... one or more digital assets combined and sequenced to create or support a learning experience addressing a curricular outcome(s) for an identified audience(s). A learning object can be identified, tracked, referenced, used, and reused for a variety of learning experiences. (Alberta Learning, 2002-2008, Online Glossary section)
\end{abstract}

LOs are also defined by their specific attributes. Williams (2002) noted that the literature identified required "criteria for learning objects" (p. 19) such as reusability, 
repurposability, granularity, and the "ability to adjust to the needs of the context in which they are being used" (p. 19). McGreal (2004) expanded on these attributes, and a list proposed by Parmentier (1999), detailing the attributes of accessibility, interoperability, adaptability, reusability, durability, affordability, assessability, discoverability, manageability, reliability and retrievability. The concept of granularity (Wiley et al., 1999) must also be considered as an attribute in order to define how large or small a LO may be.

The vagueness and openness of some of the proposed definitions has led some authors (e.g., Downes, 2003-2008; Friesen, 2001; Mortimer 2002) to posit that LOs could in fact be defined as "anything and everything" (McGreal, 2004, p. 8). Rehak and Mason (2003) concluded that: "In this environment of uncertainly and disagreement, the various stakeholders are going off in all directions" (p. 20). Wiley (2006-2008) reached a similar conclusion noting that "no one can agree about what a learning object is" ("RIP-ping on Learning Objects", para. 1). As Haughey and Muirhead (2005a) observed, "The definition of a learning object has become more complex as software engineers, instructional designers, content specialists, researchers, and educators have all sought to turn the notion of reusable digital resources into reality" (p. 470).

Murphy (2004) argued that despite divergent definitions for LOs and attributes, it is still unclear how these concepts are operationalised in actual practice. Part of this difficulty is due to the fact that the definitions proposed for objects and attributes have largely been derived theoretically. She argued that an alternative approach to defining and conceptualising objects and their attributes would be to do so from a practical and not a theoretical perspective.

The purpose of the study reported on in this paper was to gain insight into how instructional designers conceptualise LOs and their attributes, not from a theoretical perspective, but from a design perspective. It aimed to identify the range and types of conceptualisations of $\mathrm{LO}$ attributes held by a group of designers.

\section{Literature review}

While much has been written on the theory of LOs, only a few studies were identified that investigated instructional designers' practices in creating them. This section presents some practice based studies involving LOs. No studies were identified that directly investigated the meanings and interpretations held by instructional designers about LOs and their attributes.

Murphy (2004) conducted a study in which she investigated how certain attributes of LOs might be operationalised when developing an online learning module. Her study was premised on the argument that while LOs and its attributes are defined in theory, it is unclear how, in practice "they actually translate into courses or modules that can be used for instructional purposes" (Introduction section). Findings revealed detail about how certain LOs attributes were operationalised. The author concluded that this study served as a preliminary investigation into moving from theory to practice in the use of a LO approach to designing instruction. This approach was successful in terms of the attributes that were examined.

Muzio, Heins and Mundell (2002) reported on the experiences of instructional designers using LOs at a Canadian university. Instructional designers built courses 
using a database driven tool to create, contribute and retrieve LOs for the purposes of online course development. LOs were built using templates designed by instructional designers. The authors found that creating sophisticated templates was costly in terms of time and money; however, the use of generalisable simple templates was effective in speeding development and lowering costs. The authors confirmed that LOs cannot be combined in myriad ways, as was originally suggested by Hodgins (2000), but rather only certain objects can be combined with other objects to form larger structures, as suggested by Wiley (2002b).

Krauss and Ally (2005) conducted a case study to examine the challenges and issues instructional designers face when developing a LO for healthcare related subject. Their study examined theories of learning and cognition that may influence the design of LOs by using an available instrument and methodology for assessing the LO quality. The authors concluded that it is important to inform instructional design decisions about the scope of a LO and the sequence of instruction from users as well as theories of learning and cognition. The authors concluded that more time should be devoted to exchanging best practices for designing and applying LOs to instructional contexts than on developing the content itself.

Christiansen and Anderson (2004) conducted a study to determine how instructors and course designers typically use LOs. Study participants designed post-secondary course content using as many publicly available LOs as possible. The study followed a development research design and presented three case studies from different academic subject areas. The three course development teams were able to ultimately produce full courses or revisions using the approach, despite encountering many problems attempting to create full courses from LOs. There were varying levels of satisfaction with the approach to course design among the development teams.

Elliott and Sweeney (2008) conducted a case study to examine the efficiencies gained though the use of existing LOs to support a healthcare course in contrast with having to develop new LOs. They found that the approach whereby they focused on using existing materials promoted a threefold advantage in development time and a reduced cost. Additionally, they reported that gaining permission to use materials was not found to be a significant problem and some difficulties were noted in ensuring that existing LOs suitably matched the context of instruction.

There is a common theme to the purposes of the studies reviewed in this section. These studies involve reports (case study or experiential) on the experiences of instructional designers that have developed LOs or courses that consist mainly of LOs. The studies describe meanings and definitions of LOs from the literature as a fundamental starting point whereas the purpose of the present study is to gain insight into the meanings, understandings and interpretations of LOs and their attributes from the reverse angle: not from a theoretical perspective but from a design perspective.

The present study focused on a group of instructional designers who have developed LOs and have been through an equivalent training experience relating to the creation of LOs. The present study used an inductive approach to identify how instructional designers understand and interpret LOs and their attributes and therefore which attributes are most important to them in their professional practice. 


\section{Methods}

\section{Participants}

The 10 designers participating in the study were all instructional designers working at Canadian universities or colleges. They all attended the Camp CLOE one-week summer workshop on LOs and also have created objects as part of their professional practice. Four of these designers had attained a master's degree as their highest education level, two were enrolled in graduate programs in education, one had attained a PhD, two had non-education bachelor degrees and another without a degree learned instructional design on the job. Seven had been instructional designers for five years or more while three had less than five years of experience.

\section{Data collection}

Data were collected in Northern spring 2006 via two semi-structured phone interviews with each of the designers. Interviews for both phases of the study were approximately one hour in length. We completed two pilot interviews in advance of each data collection phase in order to test the interview protocol and interview guides.

The purpose of the first interview phase was to identify the range and types of conceptualisations for LOs held by the designers and to identify how designers conceptualised object attributes based on their experiences from a recent LO design project. The purpose of the second interview phase was to validate results from Phase I interviews. Designers were provided an opportunity to modify any of their responses from Phase I interviews, and were prompted to probe more deeply into common categories and subcategories derived and coded from the first phase.

\section{Data analysis}

Open coding was used to analyse, compare and create categories for the data. Strauss and Corbin (1990) described three methods of open coding, namely "line-by-line analysis, analyzing whole sentences or paragraphs, and perusing the entire document" (pp. 119-120). We used the latter two methods in this study to code the raw data. Whole sentences and paragraphs from the transcribed interviews were used to populate the branches of a concept map with text to be used to support category development. FreeMind, an open source concept mapping software application (FreeMind Website, 2006-2008), was used to assist with coding.

Possible categories and related properties from the keyword comments were noted. Categories represented recurrent concepts noted from interviews while properties served as concept modifiers. It was possible to code multiple prospective categories per keyword line, a single prospective category, or no categories at all. The categories were occasionally derived from specific words used by designers.

Next, axial coding was used to determine relationships between categories. Strauss and Corbin (1990) described axial coding as "the process of relating categories to their subcategories, termed 'axial' because coding occurs around the axis of a category, linking categories to the level of properties and dimensions" (p. 123). We completed axial coding using constant comparisons between the electronic interview notes (with the related coding) and the creation of specific "memos" (Strauss \& Corbin, p. 110) that delineated observed relationships between categories. Memos were tracked using the 
FreeMind software. Memos were not used simply to track ideas or serve as reminders; they were involved in the formulation and revision of theory during the coding process.

Finally, selective coding was the used to determine which categories were related to the core category. The core category was connected to various related categories and served as the category found with greatest frequency, connectivity, and overall importance based on coding data. Once the core category emerged, coding ceased for sentences that did not relate to that category or any of its connected categories. Relationships were captured in a hierarchical, linked format (the core category serving as the top of the hierarchy) and served as the framework for reporting the findings of the research in terms of attributes. These results were then compared with LO definitions and attributes found in the literature.

\section{Findings}

We present our findings as themes in the attributes. These are: digital, interactive, pedagogically purposeful, pedagogically worthwhile, pedagogically assessable, usable, reusable, peer reviewable and granular. We present each of these attributes separately. Pseudonyms are used in order to promote the confidentiality of participants. Where possible, we use verbatim quotes from the interviews in order to give voice to the designers who participated in the study.

\section{Digital}

Sally argued that "it's helpful to draw a line somewhere when defining learning objects." The defining feature for many participating designers was that a LO is digital." Beatrice reinforced Sally's argument: "...in terms of the definition of learning objects, unless you want to open it up to any resource you can use for learning, that [digital] would be one of the things that would limit the definition of learning objects." As Sally observed, there is a consensus among designers that "at this point in time ... when you use the term learning object, you're talking about a digital learning object." Deborah explained that LOs are "necessarily online so they have to be digital."

Not all designers supported the defining feature of LOs as digital. Susan noted: "I've used digital and non-digital learning objects in the classroom, and I don't see any distinction between them besides the fact that one is on the computer and one is not." She believed that contextualisation is more important than being digital: "A nondigital learning resource is an object if it's contextualised in some structure and organisation."

\section{Interactive}

Susan emphasised the important role that interactivity plays in the design of objects argued that "Interactivity is a requirement for good teaching. It's a requirement for a good learning object." LO interactivity was defined along a continuum from low to high level interactivity. The ends of this continuum according to Susan were represented by the use of "engaging text" (lower level) in a LO to the use of activities that promote "students actively doing something" (higher level) within an object. John elaborated on the differences between these types of interactivity: "if you watch a video clip and then do some multiple choice questions [in a LO, then] that would be low level. Higher level involves critical thinking." Richard commented that the degree 
of interactivity in a LO may necessarily be low for objects that were designed for solitary use: "since a lot of learning objects would be done by people on their own, [achieving high level interaction] will be hard."

\section{Pedagogically purposeful}

Sally described LOs as follows: "Structured with a very careful intention and instructional design leading to a specific outcome or outcomes." According to Richard, LOs provide the pedagogy that would normally come from the instructor or pedagogue. "...if it's a multimedia environment, perhaps without the presence of an instructor ... the students need to understand why they're doing it." Their pedagogical purpose may not be explicitly stated but it is essential nonetheless especially when students are in online environments. Susan argued that a well-designed LO does not need "overt statements of learning outcomes; its whole instructional design is such that it screams the objectives of the activity." John cautions against overtly stating the purpose: "excluding the explicit learning objectives or learning outcomes actually makes the object more reusable."

\section{Pedagogically worthwhile}

According to Richard, LOs are worth investing in when it involves "something that's difficult to teach." He explained further: "If there's an identified bottleneck, [then] a learning object can allow students to better learn about the concept, student performance will improve and possibly instructor time devoted to the concept will be diminished..." Alex echoed a similar belief about LOs: "If you take something that's really hard to explain in words or hard to explain by drawing on a two-dimensional surface, maybe a movie or a 3-D animation or some other way of showing it, and then they really get [it] and that's really worthwhile." Richard argues that LOs should do more than simply meet a need: "... if I had to put my money on which learning object to build, I would put it into one that addresses the need but also serves to motivate students." Sally noted that a LO is "going to address something challenging, something that might require revisiting, something that can't necessarily be done in one visit." Likewise Susan argued "if you're going to spend thousands of dollars building a learning object you may as well address an area that is known to be difficult."

\section{Pedagogically assessable}

Eileen argued that "learning objects should minimally offer an opportunity for self assessment." Assessment is an important attribute in a LO according to Richard because "Part of the learning paradigm is helping students find ways to check their understanding." Richard believed that LOs should have "some kind of feedback to help guide them [students]." Assessment is important to Deborah who asked, without it "how would you be sure that students actually learned something?" In a similar vein, Sally believed that "it could be a learning object [without assessment] but I don't think it would be a very good one."

Assessability is linked with the attribute of pedagogically purposeful. John argues "...I don't consider a picture or a sound file to be a learning object; [students] lack an opportunity to interact, an opportunity to self assess, [and] they lack defined outcomes." Alex argues that feedback and critical analysis are important to LOs: 
The static graphic is not a learning object in my opinion. However, if you build an activity around a static image asking the students for critical analysis or observation, and the student does those activities and gets some feedback on those activities, then that serves as a learning object.

\section{Usable}

Joyce argued that if an object is not usable, it "won't be used to build or enhance courses; the same could be said of learning object repositories." She emphasised that "If people have to go through a lot of hoops to use it, they won't use it." When asked why usability is a required element of LOs, Eileen noted: "Because I consider an essential component of a learning object to be producing a positive effect on learning, the outcome of that part of my definition would mean that it has to be easy to use."

\section{Reusable}

Alex argued that reusability is a fundamental feature of LOs: "It's why you make learning objects; otherwise you would hardcode them into a web course or a learning management system." For Alex, reusability means LOs "can be shared with other people." For Sally, it means the LOs "work in different learning contexts." They are: "a resource that people can adapt to customise to their own settings." The customisation means, as John explains, that "the learning object has to work for the situation you're designing for and hopefully it will work for other situations too." In his designs, John tries to accommodate reusability. He gives an example of how he facilitates the attribute: "if we're building an object for psychology, then we don't put the course name in the code of that object; we are cognisant of reuse." While he values reusability, he does not believe it should trump other needs: "My position would be that we not sacrifice the needs of the course or the program for reusability."

\section{Peer reviewable}

Susan argued in favour of peer review of LOs because "...the content has to be accurate." Richard argued regarding the process of creating LOs that "there should be someone with an instructional design background, if not involved in the process, than at least overseeing the process observing and looking in, or at some point peer reviewing it." The peer review takes on a greater role when the LO is being used outside of the institution according to Eileen:

If the learning object is to be used for widespread distribution, then it should be peer reviewed. The content should undergo some scrutiny, as well as the overall functionality of the object, to make sure but it is working and also from the instructional design standpoint.

John explains why peer review is important when LOs are shared: "If the object is in a repository, then that represents the institution. An institution has its reputation to protect." John does state one exception to the need for peer review: "On the other hand, pieces that were not peer reviewed might be useful and valid to another educator. In a way, they do a peer review before they choose to use it."

\section{Granular}

Joyce defined minimum object size in terms of evaluation: "there has to be enough substance to it to permit some form of evaluation." Deborah described LO size in 
terms of objectives. She explained how she builds LOs "to address one learning objective at a time. It could be more than one learning objective depending on the audience." Sally referred not to one objective at a time but to one theme: "I don't think it can be as big as a course. It has to have a single theme. It could, however, cover more than one learning outcome. Beatrice associates LO size with the concept of sitting: "You should be able to deal with this learning object in one sitting... whether or not that sitting is 30 seconds, a minute or two hours."

Alex defined LO size in temporal terms:

\begin{abstract}
My view of a learning object is something that a learner will interact with in a period from 15 to 45 minutes; therefore, the scope of a learning object has a temporal component ... a few seconds is too short for a learning object. If it goes beyond an hour then maybe it's a more of a course or a tutorial ... I think there is a trade off between size and reusability. It gets much more difficult to reuse in total as it gets bigger. A course can possible to serve as a learning object, but unlikely. I think the general notion is that they're smaller than a course.
\end{abstract}

\title{
Discussion
}

Instructional designers are designing and creating things that they are calling LOs. The designers in this study have participated in equivalent training on LO design and development and have created at least one LO as a result of that training. Designers in this study have similar academic and professional preparations for the instructional design profession and work in similar professional settings with similar demands. Despite this equivalent training and development experience, and professional snd academic backgrounds, even the meanings, understandings and interpretations of LOs and their attributes held by designers in this study are divergent. This perspective is consistent with the literature on LOs, as there is no commonly accepted definition for a LO (Downes, 2003-2008; Friesen, 2004; McGreal, 2004; Wiley, 2002a). Mortimer (2002) also agreed that no single definition exists for a $\mathrm{LO}$ and contended the term can hold different meanings for different people.

While designers generally defined most LO attributes in a manner consistent with definitions from the literature, they approached their definitions with interesting variances. For example, when asked, "how large may a learning object be" (in order to assess a designer's view of the acceptable granularity of a LO) many designers referred to the amount of time required for a learner to use the object (e.g., "no longer than 45 minutes" or "must be used in one sitting"). They justified their claim by highlighting what a reasonable attention span would be based on adult learning principles. In contrast, the literature on granularity refers mainly to curricular structure or technical detail, for example, the size of a course, learning objective or learning outcome (e.g., Downes, 2003-2008). In other cases, it refers to what level of granularity would allow a LO to be best housed and retrieved from searchable databases. While the concepts of learning principles and required structure are linked, it is of interest that designers chose to express their views of acceptable granularity with a focus on pedagogical best practice rather than any mention of technical definitions of LOs and their attributes.

Attributes commonly cited in the literature but not represented by the designers included affordability, reliability, discoverability, durability, manageability and scalability. Accessibility was not reported by designers as a required object attribute despite the fact that this attribute is commonly referenced in the literature (Duval et al., 
2003; Parrish, 2004; Vargo et al., 2003). Accessibility is a pivotal attribute of LOs since if they are not accessible they cease to be usable. It is possible that the designers did not reference this attribute because they are primarily using objects that they have designed themselves as opposed to objects retrieved from a repository. Haughey and Muirhead (2005a) emphasised that the design of LOs should take into consideration scaffolding and cultural context. The designers in this study did not report on these as attributes.

If, as Wiley (2002a) argues, the purpose of LOs is to provide access to better learning resources then it is not surprising that the designers referenced the pedagogical power of LOs. Likewise, Duval, Hodgins, Rehak and Robson (2003) describe the role of LOs as increasing the effectiveness of learning. The pedagogical importance of LOs was emphasised by Haughey and Muirhead (2005b) who observed that learning objects "do not have value or utility outside instructional contexts. Their value is in their application to classroom settings and to online environments where teachers may or may not be present" (Introduction section).

Not only did the designers reference the pedagogical importance of LOs, they stressed that objects should address concepts that are difficult to teach using conventional methods. Additionally, they noted that LOs should contain learning objectives to allow learners to better predict their path of instruction and therefore better plan their learning experience. However, as one participant noted, it is not clear how this attribute relates to that of reusability and whether if learning objects contain specific outcomes or objectives, they will be less reusable. Friesen's (2004) argument that LOs should be pedagogically neutral contrasts with the designers' preference for embedded outcomes.

These observations from the study's data and the comparisons of designers' statements about LO attributes, categories and analogies suggest that the designers in this study define and conceptualise LO and their attributes with more of a focus on pedagogical best practices rather than a focus on technical definitions of LOs and their attributes. Alternately stated, when designing or creating LOs, the designers appeared to focus more on the learning aspect of the term "learning object" rather than the object part of the term. This bias toward technical definitions for LOs has been previously noted in the literature by authors who maintain that the use of the term object was originally borrowed from computer science, specifically the concept of object oriented programming (Bratina, Hayes \& Blumsack, 2002; Robson, 1999).

\section{Conclusions and implications}

The purpose of the study reported on in this paper was to gain insight into how instructional designers conceptualise LOs and their attributes. It aimed to identify the range and types of conceptualisations of $\mathrm{LO}$ attributes held by a group of designers who work in post-secondary environments. It did not focus on instructional designers who work in corporate, military or government environments. Designers participating in this study were employed primarily by Canadian, publicly funded universities and college systems that are members of the CLOE network. These universities and colleges are located in mainly urban areas across Canada. Participation from designers from other geographical areas and with different professional backgrounds might have yielded different perspectives on LOs. 
Soliciting participation from the group of designers involved with Camp CLOE presented the advantage that these designers had familiarity with LOs and the advantage that these designers developed at least one object. However, it is possible that certain concepts relating to LOs and their attributes presented by CLOE or the University of Waterloo's LT3 centre during Camp CLOE were reported with a greater frequency by this group.

Some LOs considered in this study (e.g., objects from CAREO or MERLOT) were examined only from the perspective of the prospective user, not the original object developer. The source code of these LOs and their associated data structures was not examined. The study did not consider other aspects of objects such as how they are meta-tagged or how designers interpret meta-tagging. The study did not directly consider the place of standards (e.g., CanCore, IMS-LD) as they relate to LOs or how designers use $\mathrm{LO}$ repositories.

Finally, the lack of agreement in the literature about LO definitions and definitions of their attributes must be considered a limitation of this study. It is possible that, despite sharing a common LO training experience, study participants could report on LO attributes with a significantly different use of language or terminology.

With respect to the LO attributes that were stated by designers but not found in the literature (i.e., pedagogically assessable, pedagogically purposeful), it would be of interest to explore these further in order to understand whether other designers in other settings consider these to be important. It is also possible that authors use other terms to describe these attributes.

Finally, it may be of value to consider different types of LO definitions and definitions of attributes between the areas of theory and practice. Differing definition frameworks may be useful for those approaching the LO problem from either the point of view of instructional design or computer science.

\section{References}

Alberta Learning (2002-2008). Learn Alberta glossary. [viewed 21 Nov 2005, not found 13 Sep 2008] http: / / www.learnalberta.ca / Browse.aspx?View=Glossary

Barritt, C. \& Alderman Jr., F. L. (2004). Creating a reusable learning objects strategy. San Francisco: Pfeiffer.

Bratina, T. A., Hayes, D. \& Blumsack, S. L. (2002). Preparing teachers to use learning objects. The Technology Source. [viewed 4 Jul 2006, verified 13 Sep 2008] http: / / technologysource.org/article/ preparing_teachers_to_use_learning_objects /

CAREO Website (2005-2007). http: / / www.careo.org/ [viewed 26 Nov 2005]

Christiansen, J. A. \& Anderson, T. (2004). Feasibility of course development based on learning objects: Research analysis of three case studies. International Journal of Instructional Technology and Distance Learning. March 2004. http:/ / www.itdl.org/Journal/Mar_04/article02.htm [viewed 22 Sep 2005, verified 13 Sep 2008]

CLOE Website (2005-2007). http: / / cloe.on.ca/ [viewed 26 Nov 2005, not found 13 Sep 2008, see http: / / learnware.uwaterloo.ca/ projects/CCCO/cloe_stories.html]

Downes, S. (2000-2008). Learning objects. http: / / www.downes.ca/ files / Learning_Objects.htm [viewed 22 Oct 2005, verified 13 Sep 2008] 
Downes, S. (2003-2008). Paper tissue argument. http:/ / www.downes.ca/ [viewed 21 Nov 2005, not found 13 Sep 2008]

Duval, E., Hodgins, W., Rehak, D. \& Robson, R. (2003). Introduction. In E. Duval, W. Hodgins, D. Rehak \& R. Robson (Eds.), Learning Objects 2003 Symposium: Lessons learned, questions asked. Ed-Media 2003, Honolulu, HI. [verified 13 Sep 2008] http:/ / www.aace.org/conf/edmedia/LO2003Symposium.pdf

Elliott, K. \& Sweeney, K. (2008). Quantifying the reuse of learning objects. Australasian Journal of Educational Technology. 24(2). 137-142. http:/ / www.ascilite.org.au/ajet/ajet24/ elliott.html

FreeMind Web site (2006-2008). http: / / freemind.sourceforge.net/ [viewed 21 May 2006]

Friesen, N. (2001). What are educational objects? Interactive Learning Environments, 9(3), 219-230.

Friesen, N. (2004). Three objections to learning objects. In R. McGreal (Ed.), Online education using learning objects. London: Routledge/Falmer.

Haughey, M. \& Muirhead, B. (2005a). The pedagogical and multimedia designs of learning objects for schools. Australasian Journal of Educational Technology, 21(4), 470-490. http:/ / www.ascilite.org.au/ajet/ajet21/haughey.html

Haughey, M. \& Muirhead, B. (2005b). Evaluating learning objects for schools. E-Journal of Instructional Science and Technology, 8(1). http:/ / www.ascilite.org.au/ajet/ejist/docs/vol8_no1/fullpapers/eval_learnobjects_school.htm [viewed 15 Feb 2008]

Krauss, F. \& Ally, M. (2005). A study of the design and evaluation of a learning object and implications for content development. Interdisciplinary Journal of Knowledge and Learning Objects, 1(1). http:/ www.ijklo.org/Volume1/v1p001-022Krauss.pdf [viewed 20 Oct 2006]

McGreal, R. (Ed.) (2004). Online education using learning objects. London: Routledge/Falmer.

MERLOT Website (2005-2008). http: / / www.merlot.org / [viewed 26 Nov 2005]

Mortimer, L. (2002). (Learning) objects of desire: Promise and practicality. Learning Circuits. http:/ / www.learningcircuits.org/2002/apr2002/mortimer.html [viewed 23 Nov 2005]

Murphy, E. (2004). Moving from theory to practice in the design of Web-based learning using a learning object approach. E-journal of Instructional Science and Technology, 7(1). http: / / www.ascilite.org.au/ajet/e-jist/docs/Vol7_No1/FullPapers/Theory_to_practice.htm [viewed 23 Nov 2005]

Muzio, J., Heins, T. \& Mundell, R. (2002). Experiences with reusable e-learning objects: From theory to practice. Internet and Higher Education, 5(1), 21-34.

Parrish, P. (2004). The trouble with learning objects. Educational Technology Research $\mathcal{E}$ Development, 52(1), 49-67.

Parmentier, M. (1999). The ABILITIES list of content enablers. Internet Time. [viewed 2 Oct 2005, not found 13 Sep 2008] http:/ / www.internettime.com/itimegroup/astd_web/ capture.htm

Rehak, D. \& Mason, R. (2003). Keeping the learning in learning objects. In A. Littlejohn (Ed.), Reusing online resources: A sustainable approach to e-learning. Kogan: London.

Robson, R. Object-oriented instructional design and Web-based authoring. http:/ / citeseer.nj.nec.com/327280.html [viewed 4 July 2006, not found 13 Sep 2008]

Sosteric, M. \& Hesemeier, S. (2004). A first step toward a theory of learning objects. In R. McGreal (Ed.), Online education using learning objects. London: Routledge/Falmer. 
Strauss, A. \& Corbin, J. (1990). Basics of qualitative research: Grounded theory procedures and techniques. London: Sage Publications.

Vargo, J., Nesbit, J. C., Belfer, K. \& Archambault, A. (2003). Learning object evaluation: Computer-mediated collaboration and inter-rater reliability. International Journal of Computers and Applications, 25, 198-205.

Wiley, D. A., South, J. B., Bassett, J., Nelson, L. M., Seawright, L. L., Peterson, T. \& Monson, D. W. (1999). Three common properties of efficient online instructional support systems. The ALN Magazine, 3(2). http:// www.sloan-c.org/publications/magazine/v3n2/ wiley.asp [viewed 26 Nov 2005, verified 13 Sep 2008]

Wiley, D. A. (Ed.) (2002a). The instructional use of learning objects. Bloomington, IN: Agency for Instructional Technology and the Association for Educational Communications and Technology. http: / / www.reusability.org/read/

Wiley, D. A. (2002b). Connecting learning objects to instructional design theory: A definition, a metaphor, and a taxonomy. In Wiley, D.A. (Ed.), The instructional use of learning objects. Bloomington, IN: Agency for Instructional Technology and the Association for Educational Communications and Technology. http: / / www.reusability.org/read/chapters/ wiley.doc

Wiley, D. A. (2006-2008). RIP-ping on learning objects. Iterating toward openness: Wiley Blog. http: / / opencontent.org/blog/ [viewed 2 Feb 2006]

Williams, D. (2002). Evaluation of learning objects and instruction using learning objects. In D. Wiley (Ed.), The Instructional Use of Learning Objects. Bloomington, IN: Agency for Instructional Technology and the Association for Educational Communications and Technology. http:/ / www.reusability.org/read/ chapters/ williams.doc

David E. Francis, Academic Director, Virtual Campus

Saskatchewan Institute of Applied Science and Technology (SIAST)

400 - 119 4th Avenue South, Saskatoon, Saskatchewan S7K 5X2, Canada

Email: francisda@siast.sk.ca

Associate Professor Elizabeth Murphy, Faculty of Education

Memorial University, St. John's, Newfoundland A1B 3X8, Canada

Email: emurphy@mun.ca 